\title{
Tamoxifen-induced ER- $\alpha-$ SRC-3 interaction in HER2 positive human breast cancer; a possible mechanism for ER isoform specific recurrence
}

\author{
Marie Mc Ilroy 1,2, Fergal J Fleming ${ }^{1,3}$, Yvonne Buggy ${ }^{1}$, Arnold D K Hill ${ }^{2,3}$ and \\ Leonie S Young ${ }^{1,2}$
}

${ }^{1}$ UCD Conway Institute, University College Dublin, Dublin, Ireland

${ }^{2}$ Department of Surgery, Royal College of Surgeons in Ireland, Dublin, Ireland

${ }^{3}$ Department of Surgery, St Vincent's University Hospital, Dublin, Ireland

(Requests for offprints should be addressed to L S Young who is now at Department of Surgery, Royal College of Surgeons in Ireland, St Stephens Green, Dublin 2, Ireland; Email: lyoung@rcsi.ie)

M Mc Ilroy and F J Fleming contributed equally to this work

\begin{abstract}
Differential signalling between the two oestrogen receptor (ER) isoforms in the presence of tamoxifen has been described. We hypothesise that differential recruitment of the steroid receptor co-activator, SRC-3 to ER- $\alpha$ and ER- $\beta$ may in part explain associations between ER isoforms and response to endocrine treatment. SRC-3 was localised within epithelial cells of breast tumour tissue and was co-localised with ER- $\alpha$ and ER- $\beta,(n=112)$. Expression of SRC-3 was found to be positively associated with ER- $\alpha(P=0.0021)$ and inversely with $\operatorname{ER}-\beta(P<0.0001)$. Uniquely, this study utilises primary cell cultures derived from patient tumours, thus providing samples not readily available in most molecular model systems. These samples have enabled us to investigate the influence of growth factor pathways on steroid receptor-co-activator interactions. In HER2 (human epidermal growth factor receptor 2) positive primary tumour cell cultures $17 \beta$-estradiol induced a decrease in SRC-3, whereas upregulated SRC-3 expression. Furthermore, treatment with tamoxifen-induced SRC-3 recruitment to the ER-oestrogen response element and enhanced interaction between SRC-3 and ER- $\alpha$, but not ER- $\beta$. Knockdown of SRC-3 results in a concomitant loss of expression of the oestrogen target gene pS2. Furthermore, silencing of SRC-3 resensitizes endocrine resistant, HER2 positive cells to the anti-proliferative effects of tamoxifen. The ability of ER- $\alpha$, but not ER- $\beta$ to recruit SRC-3 in the presence of tamoxifen may in part explain the differential ER isoform associations with recurrence in human breast cancer.
\end{abstract}

Endocrine-Related Cancer (2006) 13 1135-1145

\section{Introduction}

Breast cancer continues to affect one in ten women in the western world and despite the phenomenal advances in recent years, the mortality rate still remains at around 35\%. Oestrogen receptors (ER) play a pivotal role in normal breast development and in the initiation and progression of breast cancer, hence, disruption of ER function is the main therapeutic strategy employed in targeting the disease. The ER is encoded for by two genes, ER- $\alpha$ and ER- $\beta$. Variation between the different ER isoforms transcriptional activation and in vivo tumour formation, in response to $17 \beta$-estradiol and tamoxifen has been described (Paech et al. 1997, Paruthiyil et al. 2004). This has led to the hypothesis that each isoform may play distinct roles in tumour progression. Studies at an mRNA level have associated ER- $\beta$ with disease progression (Speirs et al. 1999), however, ER- $\beta$ protein levels have been related to a positive response to endocrine therapy and increased disease-free survival (Mann et al. 2001, Fleming et al. 2004a, Myers et al. 2004). 
Many breast cancer tumours that are initially responsive to endocrine therapy will develop acquired resistance after prolonged treatment with tamoxifen whilst others display de novo resistance (Schiff \& Osborne 2005). Tamoxifen has a tissue specific agonist/antagonist profile, which is thought to be due in part, to the presence of ER coregulatory proteins. In particular, the steroid receptor-co-activator, SRC-3 (AIB-1, pCIP, RAC3, ACTR and TRAM-1) is documented to enhance the oestrogen agonist properties of tamoxifen in vitro (Smith et al. 1997). SRC-3 has been implicated in breast tumourigenesis with reports of gene amplification frequencies and increased levels of both SRC-3 mRNA and protein in breast cancer (Anzick et al. 1997, List et al. 2001, Hudelist et al. 2003). SRC-3 is an important ER- $\alpha$ co-activator and has been reported to display oncogenic properties when overexpressed in a transgenic model (Torres-Arzayus et al. 2004), in contrast, disruption of the $S R C-3$ gene in mice, results in a diverse phenotype with abnormal reproductive function and mammary gland growth retardation (Xu et al. 2000). The importance of SRC-3 in regulating ER function is further illustrated by its mediation of agonist but not antagonist-induced degradation of ER- $\alpha$. Thus loss of SRC-3 will affect ER- $\alpha$-regulated signalling by both inhibiting degradation of the receptor and subsequent quenching of transcriptional initiation (Shao et al. 2004).

There is now substantial evidence of crosstalk between the ER and growth factor receptor signalling pathways. HER2, a member of the epidermal growth factor receptor family has been implicated in de novo endocrine resistance in studies where MCF7 breast cancer cells are engineered to overexpress HER2 (Shou et al. 2004). Crosstalk between ER and this receptor has been shown to result in phosphorylation of SRC-3 thereby enhancing co-activator activity (Font De Mora \& Brown 2000). In a study of breast cancer patients, high levels of both SRC-3 and HER2 protein have been associated with tamoxifen resistance (Osborne et al. 2003).

Data presented here supports the hypothesis that ER$\alpha$ specific recruitment of SRC-3 in the presence of tamoxifen may contribute to differential associations between ER isoforms and response to endocrine therapy. We provide evidence of this using ex vivo breast tumours from patients undergoing surgery for the removal of histologically confirmed breast cancer. It was found that tamoxifen-liganded ER- $\alpha$, but not ER- $\beta$, can bind SRC-3 in the presence of HER2. Furthermore, resensitization of endocrine resistant cells to tamoxifen by silencing SRC-3 provides conclusive verification for the importance of co-activator recruitment in HER2 positive recurrent breast cancer.

\section{Materials and methods}

\section{Patient selection}

Following ethical approval, 112 breast carcinomas from patients undergoing surgery and six specimens of histologically normal breast tissue from patients undergoing reduction mammoplasties were examined. Patients were selected on the basis of those, who received tamoxifen only as adjuvant therapy after surgery. All patients had stage I-II breast cancer at presentation and were assessed by abdominal ultrasound, chest X-ray and bone scintigraphy before surgery. HER2 status was evaluated using the DAKO (Glostrup, Denmark) HercepTest immunocytochemical assay. Scoring was assessed according to the manufacturer's instructions. A score was assigned according to the intensity and pattern of cell membrane staining: 0 to $+1=$ no staining or staining in $<10 \%$ of cells; $+2=$ weak to moderate staining in $>10 \%$ of cells; $+3=$ strong staining in $>10 \%$ of cells. In tumour samples scoring +2 with the Hercept test; HER2 status was confirmed by fluorescent in situ hybridization using the Vysis Kit (Abbot Laboratories, Illinois, IL, USA) according to manufacturers' instructions.

\section{Immunohistochemistry}

SRC-3 was detected within the archival paraffinembedded breast tumour specimens. Sections were incubated with rabbit anti-human SRC-3 $(1 \mu \mathrm{g} / \mathrm{ml})$ (sc-13066, Santa Cruz Biotechnology, Santa Cruz, CA, USA) followed by corresponding biotin-labelled secondary antibody (1:2000) using the Vectastain Elite kit (Vector Labs, Burlingame, CA, USA) according to the manufacturers instructions. SRC-3 was detected using 3, 3-diaminobenzidine tetrahydrochloride and counterstained with haematoxylin. Negative controls were performed using matched IgG controls (DAKO). Immunostained slides were scored using the Allred scoring system (Harvey et al. 1999). Two independent observers without knowledge of prognostic factors scored the slides.

\section{Clinico-pathological parameters}

Variables analysed included tumour size, tumour grade and auxiliary node status. A recurrence was defined as any local (chest wall) or systemic recurrence during the follow-up period. 


\section{Statistical analysis}

Statistical analysis was carried out using the Fishers exact test for categorical variables. Two-sided $P$-values of $<0.05$ were considered to be statistically significant.

\section{Immunofluorescent microscopy}

Breast cancer sections were blocked in goat serum, incubated with mouse anti-human ER- $\alpha(10 \mu \mathrm{g} / \mathrm{ml}$ in $10 \%$ human serum) (sc-8002, Santa Cruz) or mouse anti-human ER- $\beta$ (1:2 dilution with PBS in $10 \%$ human serum) (Serotec, Oxford, UK) followed by tetramethyl rhodamine iso-thiocyanate (TRITC)-conjugated sheep anti-mouse secondary antibody $(1: 100)$ (Sigma-Aldrich). Sections were co-incubated with rabbit anti-human SRC-3 $(10 \mu \mathrm{g} / \mathrm{ml}$ in $10 \%$ human serum) followed by fluorescein isothiocyanate (FITC) conjugated goat anti-rabbit secondary antibody (1:100) (Sigma-Aldrich). Slides were mounted using fluorescent mounting media (DAKO).

\section{Primary breast cancer cell culture and cell line stimulations}

After ethical approval and patient consent, 24 specimens were obtained from patients undergoing surgery ( 5 HER 2 + ve, 19 HER2 - ve). Primary breast cancer cultures were established and validated as previously described (Fleming et al. 2004a). Primary cultures and breast cancer cell lines, endocrine-sensitive, MCF7 (ATCC) and endocrine-resistant, MCF7-derived LY2 (kind gift from Dr Robert Clarke, Georgetown University, Washington DC, USA) were serum and steroid depleted for $24 \mathrm{~h}$ and were then incubated in the presence and absence of $17 \beta$-estradiol $\left(10^{-8} \mathrm{M}\right)$ or 4-hydroxytamoxifen (4-OHT) $\left(10^{-8} \mathrm{M}\right)$ for a further $24 \mathrm{~h}$ and harvested. Total protein was extracted using lysis buffer (1\% Ipegal, $0.5 \%$ deoxycholic acid, $0.1 \%$ SDS and 1X PBS) with pefabloc $(5 \mu \mathrm{g} / \mathrm{ml})$. Cytoplasmic and nuclear extracts were isolated using a NE PER extraction kit (Pierce, Rockford, IL, USA).

\section{Western blotting}

The protein samples from HER2 positive and negative breast tumours $(100 \mu \mathrm{g})$ were electrophoresed and transferred to nitrocellulose membrane (Bio-Rad, UK) $(n=3)$. The membrane was blocked (5\% non-fat milk), and incubated with rabbit anti-SRC-3 $(2 \mu \mathrm{g} / \mathrm{ml})$ (sc-13066, Santa Cruz) followed by corresponding horseradish peroxidase conjugated secondary antibody (Santa Cruz) (1:7500). The membrane was developed with intensified luminescence (Pierce). Western blot analysis of HER2 positive nuclear and cytoplasmic proteins examined in this study was carried out on equal amounts of cellular fraction protein extracts $(100 \mu \mathrm{g} / \mathrm{sample})$ isolated using the NE-PER Kit (Pierce). Staining the membrane with Ponceau $\mathrm{S}$ for each experiment assessed equal protein loading. All experiments were carried out in triplicate.

\section{Electrophoretic mobility shift assays (EMSA)}

EMSA was performed as previously described (Fleming et al. 2004b). After ethical approval, breast tumour specimens were obtained from patients undergoing surgery for the removal of a histologically confirmed breast tumour. The samples were cultured as described previously (Fleming et al. 2004b) and incubated in the presence and absence of 17 $\beta$-estradiol $\left(10^{-8} \mathrm{M}\right)$ and 4-hydroxytamoxifen $\left(10^{-8} \mathrm{M}\right)$ for $24 \mathrm{~h}$ and harvested. Cell lysates were prepared in an appropriate volume of lysis buffer with protease inhibitors $(0.5 \%$ Pefabloc, Roche) and normalised for protein content. After histological confirmation of the HER2 status of the sample, $2 \mu \mathrm{g}$ nuclear extract was incubated in the presence of $\alpha-\left[{ }^{32} \mathrm{P}\right] \mathrm{dCTP}-$ labelled double-stranded oligonucleotide for oestrogen response element (ERE). For supershift experiments nuclear extracts were preincubated with antibodies against ER- $\alpha$, ER- $\beta$ and SRC-3. The samples were electrophoresed through a $5.5 \%$ non-denaturing polyacrylamide gel in $0.5 \mathrm{X}$ Tris-borate-EDTA buffer. For competition studies the reaction was performed as described with $50 \mathrm{X}$ molar excess of unlabelled probe. Negative controls were nuclear extracts from the ER- $\alpha$ - and $\beta$-negative SKBR3 breast cancer cells. In order to determine the relative expression of proteins at the ERE, EMSA gels were divided, part was exposed to X-ray film to detect the ER-ERE and part was transferred to a nitrocellulose membrane $(250 \mathrm{~mA}$ for $90 \mathrm{~min})$ and was subsequently immunoblotted with antibodies directed against SRC-3. Using primary cell cultures derived from individual HER2 positive $(n=3)$ and negative $(n=3)$ tumour specimens, the experiment was carried out in triplicate.

\section{Immunoprecipitation}

Complex formation between the co-activator SRC-3 and the ER isoforms, ER- $\alpha$ and ER- $\beta$ was examined. Total cell lysate $(100 \mu \mathrm{g})$ from four primary breast cell cultures derived from HER2 positive $(n=3)$ and HER2 negative $(n=3)$ patient tumours (incubated in the presence and absence of $17 \beta$-estradiol and 4-hydroxytamoxifen) were immunoprecipitated with 
anti-SRC-3 (2 $\mu \mathrm{g})$ (sc-13066, Santa Cruz). Immunoprecipitates were collected on protein A/G-agarose (Santa Cruz). Precipitates were immunoblotted with either rabbit anti-human ER- $\alpha(2 \mu \mathrm{g} / \mathrm{ml})$ (Santa Cruz) or rabbit anti-human ER- $\beta(2 \mu \mathrm{g} / \mathrm{ml})$ (Zymed, CA USA).

\section{Downregulation of SRC-3 using siRNA}

siRNA to suppress RNA expression of the $S R C$-3 gene was generated in vitro using the Silencer siRNA Construction Kit (Ambion, Oxford, UK) utilising the following oligonucleotide sequences: siRNA-SRC-3 sense: AAAAGCGGTCCTAAGGAGTCTCCTGTCTC siRNA-SRC-3 antisense: AAAGACTCCTTAGGACCGTTC. Cells were transiently transfected using siPORT Amine transfection reagent (Ambion). siPORT Amine $(4 \mu \mathrm{l})$ and siRNA-SRC-3 $(2 \mu \mathrm{l})$ were mixed separately with Opti-minimum essential medium (MEM) (Gibco-BRL) to a total volume of $200 \mu \mathrm{l}$ and incubated at room temperature for $20 \mathrm{~min}$, the mixtures were then combined to give a final concentration of $12.5 \mathrm{nM}$ and incubated at room temperature for a further 20 min. siRNA-GAPDH (glyceraldehyde-3-phosphate dehydrogenase) and scrambled siRNA were used as controls. Cell cultures were later stimulated $24 \mathrm{~h}$ posttransfection as previously described.

\section{Immunocytochemistry}

pS2 protein was detected in transfected MCF7 breast cancer cells grown on chamber slides (Nunc, Rochester, NY, USA) using polyclonal goat antihuman antibody (1:50) (sc-7842, Santa Cruz) followed by corresponding peroxidase conjugated secondary antibody (1:200) (DAKO).

\section{Assessment of cell replication}

Cell replication was assessed by monitoring the successive halving of the fluorescence of labelled cells with every cell division. Cells were treated with a $10 \mu \mathrm{M}$ dilution of the fluorescein-based dye (CFSE) carboxyfluorescein diacetate, succinimidyl ester (Molecular Probes, Invitrogen, Paisley, UK) and incubated at $37{ }^{\circ} \mathrm{C}$ for $10 \mathrm{~min}$. At the end of the incubation period, cells were washed $\times 3$ with cold MEM containing $10 \%$ fetal calf serum (FCS) and then seeded at a density of $2.5 \times 10^{5}$ cells $/ 25 \mathrm{~cm}^{2}$. The level of fluorescence was then analysed by flow cytometry. Cell proliferation was also monitored by cell counts performed using trypan blue exclusion.

\section{Results}

\section{Localization and expression of SRC-3 in human breast cancer}

Strong positive staining for SRC-3 was detected in the nuclei of breast tumour epithelial cells and to a lesser extent within the cytoplasm, expression was absent from surrounding normal tissue and normal reduction mammoplasties (Fig. 1A). Using immunofluorescence, co-expression of SRC-3 with the steroid nuclear receptors ER- $\alpha$ and ER- $\beta$ was observed. In primary breast cell cultures, derived from HER2 positive and HER2 negative patient tumours, treatment with 4-OHT induced an increase in total protein expression of SRC-3 only in those tumours positive for HER2. Following on from this observation, SRC-3 was detected within the nuclear protein fraction and to a lesser extent within the cytosol of HER2 positive tumour cells under basal conditions with an induction observed in the nuclear fraction following treatment with 4-OHT (Fig. 1C).

\section{Correlation with clinical variables}

ER- $\alpha$ and ER- $\beta$ were found to be expressed in $88 \%$ and $59 \%$ of breast tumour patients respectively, whereas SRC-3 was detected in 53\% of breast tumours (Table 1). There was a significant association observed between the expression of ER- $\alpha$ and SRC-3 $(P=0.0021)$, whereas an inverse relationship between ER- $\beta$ and SRC-3 was observed, $(P<0.0001)$ (Table 1). No associations between the expression of ER- $\alpha$ was observed in relation to age, tumour size, histological grade and axillary node status, whereas, ER- $\beta$ protein was found to inversely associate with tumour size $(P=0.0064)$. An inverse relationship was detected between ER- $\beta$ protein expression and both HER2 status and disease recurrence $(P=0.0003$ and $P=0.0007$ respectively), conversely SRC-3 protein expression associated with HER2 status and disease recurrence on endocrine treatment $(P=0.0058$ and $P=0.0069$ respectively).

\section{Recruitment of SRC-3 to the ER- $\alpha / E R-\beta$ ERE complex}

Gel shift assays showed ER-ERE binding in human primary tumour cell nuclear extracts, derived from HER2 negative patients, under basal conditions and in the presence of $17 \beta$-estradiol and 4-OHT. Pre-incubation of nuclear extracts with anti-ER- $\alpha$ and anti-ER- $\beta$ induced a supershift, establishing the presence of both ER- $\alpha$ and ER- $\beta$ at the protein-DNA complex (Fig. 2A). Incubation of nuclear extracts with antibodies directed against 
A

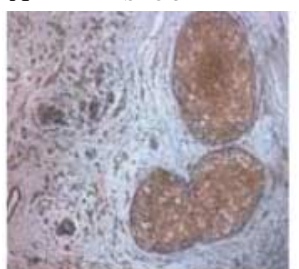

Breast tumour

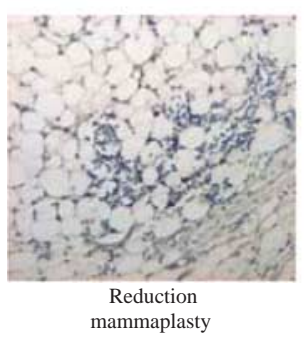

IgG Control

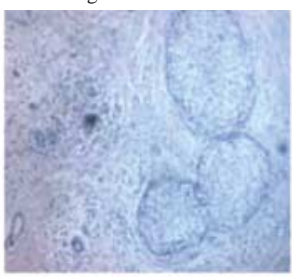

Breast tumour

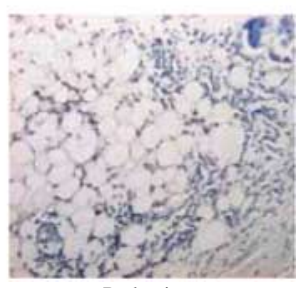

Reduction

mammaplasty

B

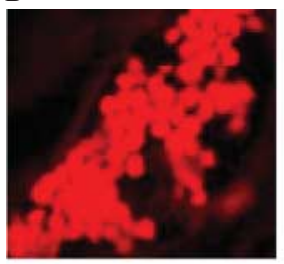

ER- $\alpha$

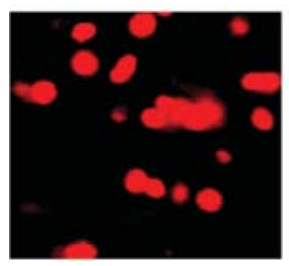

ER- $\beta$

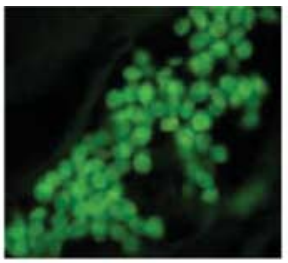

SRC-3

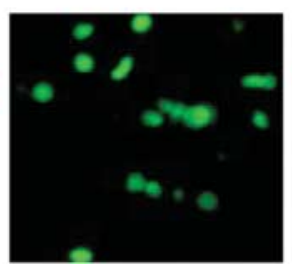

SRC-3

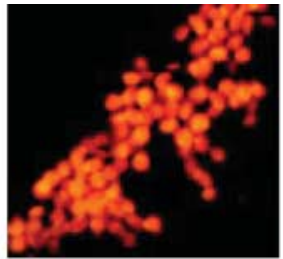

$\mathrm{ER}-\alpha+\mathrm{SRC}-3$

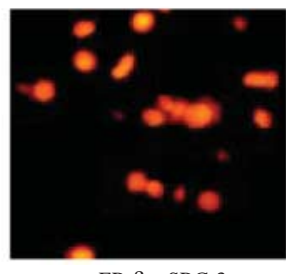

ER $-\beta+$ SRC-3
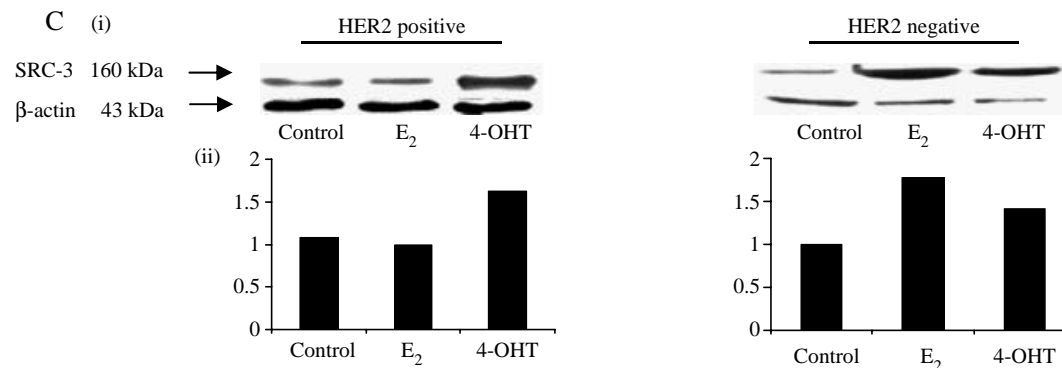

(iii)
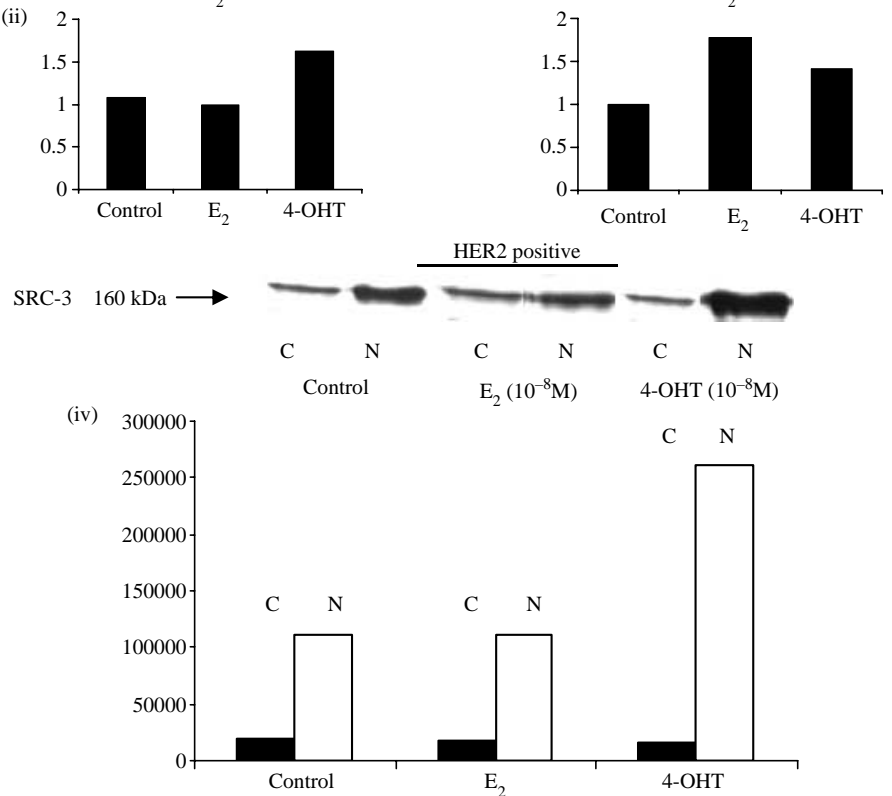

Figure 1 (A) Immunohistochemical localization of SRC-3, counterstained with haematoxylin and matched IgG-negative controls in HER2 negative human breast cancer tissue (100X) and normal breast tissue from reduction mammaplasty $(200 \mathrm{X}), n=112$. (B) Immunofluorescent colocalization of ER- $\alpha$ with SRC-3 (400X) and ER- $\beta$ with SRC-3 (400X). Results are representative of those obtained in three separate experiments. All images are derived from HER2 negative tumour samples. (C) (i) Expression of SRC-3 in total protein extracts derived from HER2 positive and HER2 negative primary tumour breast cell cultures $(n=3)$. (iii) Expression of SRC-3 in nuclear $(\mathrm{n})$ and cytoplasmic (c) protein fractions derived from HER2 positive primary tumours $(n=3)$. Cells were harvested after 24 incubation with $17 \beta$-estradiol and $4-\mathrm{OHT}\left(10^{-8} \mathrm{M}\right)$. Results are representative of those obtained in three separate experiments. Densitometric analysis of protein abundance is expressed as fold induction of protein after correction for loading controls (ii) and relative level of protein expression (iv).

SRC-3 induced a supershift under control conditions and in the presence of $17 \beta$-estradiol. However, in nuclear extracts from HER2 positive patients, treatment with 4-OHT induced a marked increase in the intensity of the SRC-3 supershift (Fig. 2A), which was not observed in HER2 negative patients (Fig. 2B). No binding was detected in nuclear extracts from ER- $\alpha$ - and $\beta$-negative SKBR3 breast cancer cells. 
Table 1 Correlation between ER- $\alpha$, ER- $\beta$ and SRC-3 protein expression with clinico-pathological parameters

\begin{tabular}{|c|c|c|c|c|c|c|c|}
\hline & Total & $\begin{array}{c}\text { ER- } \alpha \text {-positivity } \\
(\%)\end{array}$ & $\begin{array}{c}P \\
\text { value }\end{array}$ & $\begin{array}{c}\text { ER- } \boldsymbol{\beta} \text {-positivity } \\
(\%)\end{array}$ & $\begin{array}{c}P \\
\text { value }\end{array}$ & $\begin{array}{c}\text { SRC-3 positivity } \\
(\%)\end{array}$ & $\begin{array}{c}P \\
\text { value }\end{array}$ \\
\hline No. of patients & 112 & $98(88 \%)$ & - & 66 (59\%) & - & 59 (53\%) & - \\
\hline \multicolumn{8}{|l|}{ Patient age (years) } \\
\hline$\leq 50$ & 54 & $47(87 \%)$ & \multirow[t]{2}{*}{0.8863} & $28(52 \%)$ & \multirow[t]{2}{*}{0.1419} & $31(57 \%)$ & \multirow[t]{2}{*}{0.3335} \\
\hline$>50$ & 58 & 51 (88\%) & & $38(66 \%)$ & & $30(48 \%)$ & \\
\hline \multicolumn{8}{|l|}{ Tumour size (mm) } \\
\hline$\leq 30$ & 68 & $58(85 \%)$ & \multirow[t]{2}{*}{0.3802} & 47 (69\%) & \multirow[t]{2}{*}{0.0064} & 29 (43\%) & \multirow[t]{2}{*}{0.0082} \\
\hline$>30$ & 44 & 40 (91\%) & & $19(43 \%)$ & & $30(68 \%)$ & \\
\hline \multicolumn{8}{|l|}{ Histological grade } \\
\hline Grade 3 & 57 & 52 (91\%) & \multirow[t]{2}{*}{0.2246} & $34(60 \%)$ & \multirow[t]{2}{*}{0.8746} & $36(63 \%)$ & \multirow[t]{2}{*}{0.0237} \\
\hline Non-grade 3 & 55 & 46 (84\%) & & $32 / 55(58 \%)$ & & $23(40 \%)$ & \\
\hline \multicolumn{8}{|l|}{ Axillary node status } \\
\hline Node positive & 49 & $43(88 \%)$ & \multirow[t]{2}{*}{0.9426} & $25(51 \%)$ & \multirow[t]{2}{*}{0.1335} & 25 (51\%) & \multirow[t]{2}{*}{0.7566} \\
\hline Node negative & 63 & $55(87 \%)$ & & $41(65 \%)$ & & $34(54 \%)$ & \\
\hline \multicolumn{8}{|l|}{ HER-2 expression } \\
\hline HER -2 positive & 23 & $20(87 \%)$ & \multirow[t]{2}{*}{0.9296} & $6(26 \%)$ & \multirow[t]{2}{*}{0.0003} & $18(78 \%)$ & \multirow[t]{2}{*}{0.0058} \\
\hline HER-2 negative & 89 & 78 (88\%) & & $60(67 \%)$ & & $41(46 \%)$ & \\
\hline \multicolumn{8}{|l|}{ SRC-3 expression } \\
\hline SRC-3 positive & 59 & 57 (97\%) & \multirow[t]{2}{*}{0.0021} & $24(41 \%)$ & \multirow[t]{2}{*}{$<0.0001$} & - & \multirow[t]{2}{*}{-} \\
\hline SRC-3 negative & 53 & $41(77 \%)$ & & $42(79 \%)$ & & - & \\
\hline \multicolumn{8}{|l|}{ Recurrences } \\
\hline Recurrence & 20 & $18(90 \%)$ & \multirow[t]{2}{*}{0.7091} & $5(25 \%)$ & \multirow[t]{2}{*}{0.0007} & $16(80 \%)$ & \multirow[t]{2}{*}{0.0069} \\
\hline Non-recurrence & 92 & $80(87 \%)$ & & $61(66 \%)$ & & 43 (47\%) & \\
\hline
\end{tabular}

Statistical analysis performed by chi-square test.

To determine the relative expression of SRC-3 at the ER-ERE complex, the protein-DNA gels were transferred to a nitrocellulose membrane. Expression of SRC-3 was detected at the DNA complex under basal conditions and in the presence of $17 \beta$-estradiol. However, the greatest expression of SRC-3 was seen with 4-OHT in extracts from HER2 positive patients, indicating a greater recruitment of SRC-3 to the ER-ERE in the presence of 4-OHT (Fig. 2C).

The ability of the ER isoforms to differentially recruit SRC-3 in the presence of oestrogen and tamoxifen was examined using immunoprecipitation. ER- $\alpha$ interacted with SRC-3 under control conditions in nuclear extracts from both HER2 positive and HER2 negative patients. In HER2 negative patients oestrogen-induced ER- $\alpha-$ SRC-3 interactions, these interactions were abrogated by the ER modulator 4-OHT. However, in nuclear extracts from HER2 positive patients, the greatest ER- $\alpha-$ SRC-3 binding was observed in the presence of 4-OHT alone and in combination with $17 \beta$-estradiol (Fig. 3).

In contrast, ER- $\beta$-SRC-3 interactions were seen under basal conditions with increases in binding observed in the presence of 17 $\beta$-estradiol. 4-OHT was found to inhibit ER- $\beta$-SRC-3 binding in nuclear extracts from both HER2 positive and HER2 negative breast cancer patients. Furthermore, the treatment with 4-OHT abrogated the increased ER- $\beta$-SRC-3 associations, which is seen in the presence of 17ß-estradiol (Fig. 3).

\section{Downregulation of SRC-3 results in concomitant loss of oestrogen target gene pS2 and restores efficacy of tamoxifen's anti-proliferative effect in endocrine-resistant breast cancer cells in vitro}

Knockdown of SRC-3 resulted in concomitant loss of pS2 expression in MCF7 cells (Fig. 4), in comparison a knockdown of GAPDH had no effect of $\mathrm{pS} 2$ protein expression. In order to determine the effect of suppressing SRC-3 protein levels on cell replication rates we transiently transfected HER2 positive, LY2 cells with siRNA-SRC-3 prior to exposure to 4-OHT or $17 \beta$-estradiol (both $10^{-8} \mathrm{M}$ ). Mock-transfected cells were used as controls. In the siRNA-scrambled control transfected cells, both oestrogen and tamoxifen enhanced cell proliferation of the endocrine-resistant LY2 cells. In contrast, it was shown that suppression of SRC-3 resulted in reduced $17 \beta$-estradiol and 4-OHTinduced cell proliferation in LY2 cells (Fig. 5A).

In carboxyfluorescein succinimidyl ester (CFSE)labelled cells it was observed that mock-transfected cells treated with tamoxifen continued to proliferate with almost complete abrogation of fluorescence after $72 \mathrm{~h}$. In contrast, cells in which SRC-3 had been silenced, retained just over $50 \%$ of their fluorescence, indicating retarded cell proliferation (Fig. 5B). This is 


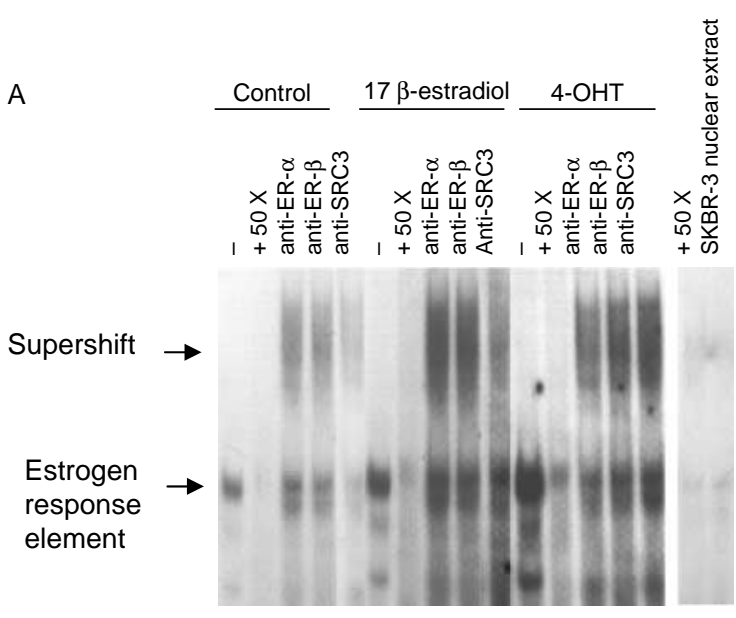

HER2 positive breast cancer cells

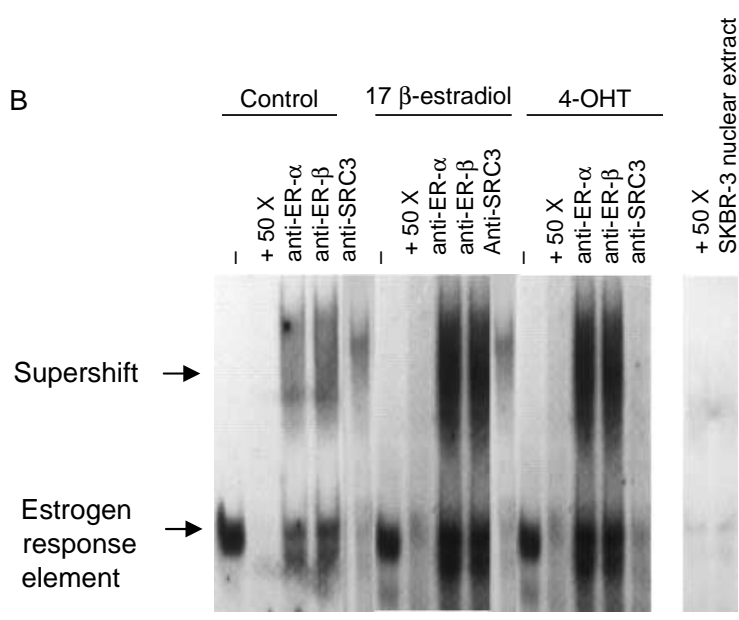

HER2 negative breast cancer cells
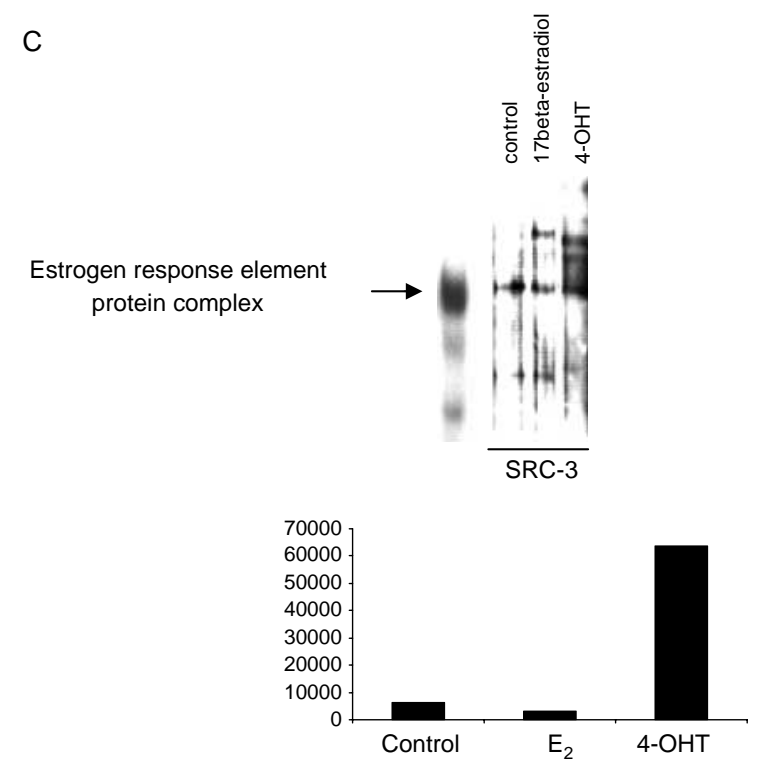

illustrated by the flow-cytometry histograms in which there is a notable shift to the right in the scrambled controls, indicating a lower median of fluorescence and greater proliferation compared with the siRNA-SRC-3 treated cells (Fig. 5B).

\section{Discussion}

Recent molecular and clinical studies have provided compelling evidence of distinct roles for ER- $\alpha$ and ER$\beta$ in breast tumourigenesis. Despite early ER- $\beta$ mRNA associations with tumour grade and poor outcome (Speirs et al. 1999), we and others have described a significant relationship between ER- $\beta$ protein and a positive response to endocrine treatment (Mann et al. 2001, Fleming et al. 2004a, Myers et al. 2004). Furthermore, we have observed an inverse association between ER- $\beta$ expression and the growth factor receptor HER2 (Fleming et al. 2004b). Expression of ER- $\beta$ as a beneficial prognostic indicator in the breast cancer may not be a simple ligand-nuclear receptor activated event. No difference between ER- $\alpha$ and ER- $\beta$ recruitment to the ERE in primary breast tumour cells has been observed in the presence of either $17 \beta$ estradiol or tamoxifen (Fleming et al. 2004b). These findings suggest that other regulatory proteins may be responsible for the lack of parity between the clinical associations of each ER isoform.

Nuclear receptors, including ER interact with co-activator proteins to drive the transcription of target genes. SRC-3 has been established as an ER co-activator protein (Suen et al. 1998) and has been implicated in breast tumour progression and resistance to endocrine therapy (Osborne et al. 2003). In line with these findings, here we describe a positive association between SRC-3 and recurrence with endocrine treatment. In this study we have observed co-localization of SRC-3 with both ER- $\alpha$ and ER- $\beta$ in human breast

Figure 2 EMSA of nuclear extracts from primary breast cancer cultures derived from (A) HER2 positive and (B) HER2 negative tumours. Nuclear protein extracts from primary breast cancer cells in the presence and absence of 50X molar excess of homologous oligonucleotide. Nuclear protein extracts were preincubated in the presence of anti-ER- $\alpha$, anti-ER- $\beta$ or antiSRC-3. Nuclear extracts from ER- $\alpha$ - and $\beta$-negative SKBR3 breast cancer cells were used as negative control. Images are representative of results obtained from separate experiments utilising three individual patient tumour samples for each group. (C) The relative expression of SRC-3 at the ERE was examined by transfer of the DNA-protein blot to a nitrocellulose membrane and subsequently immunoblotting with anti-SRC-3 $(n=3)$.

Densitometric analysis of the levels of protein under different conditions is represented with a histogram, expressed as relative levels of SRC-3 protein abundance at the ERE. 
SRC-3 immunoprecipitates

(i)
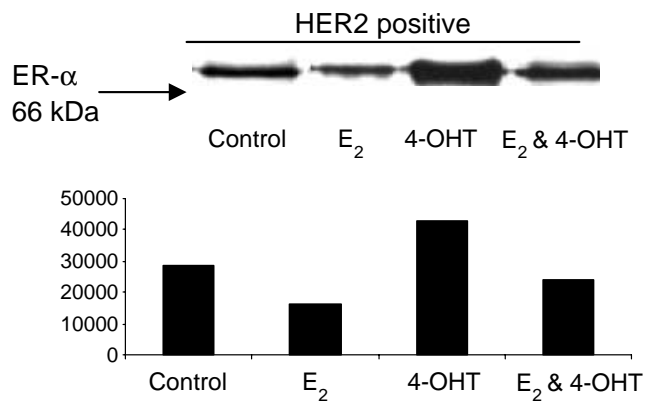

(ii) ER- $\beta$
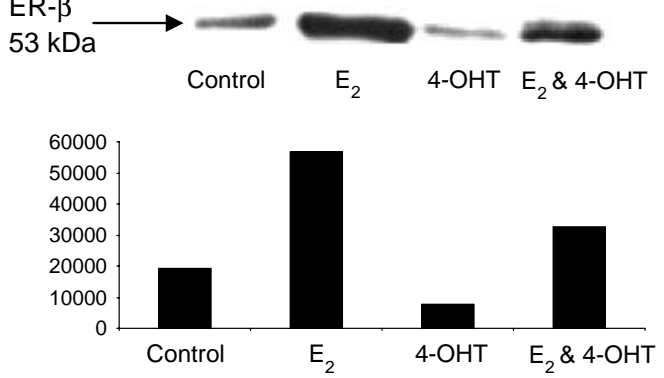

(iii)
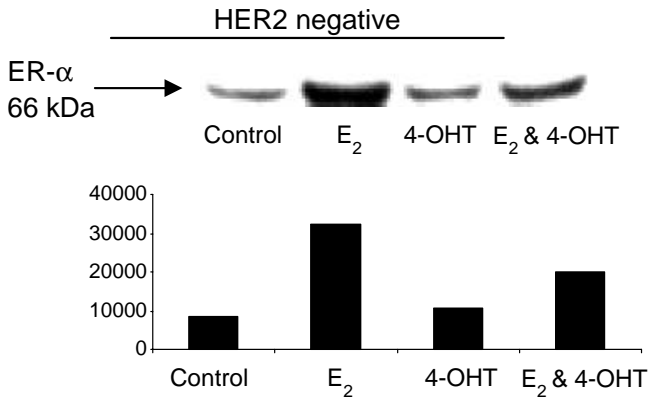

(iv) $\mathrm{ER}-\beta$ $53 \mathrm{kDa}$
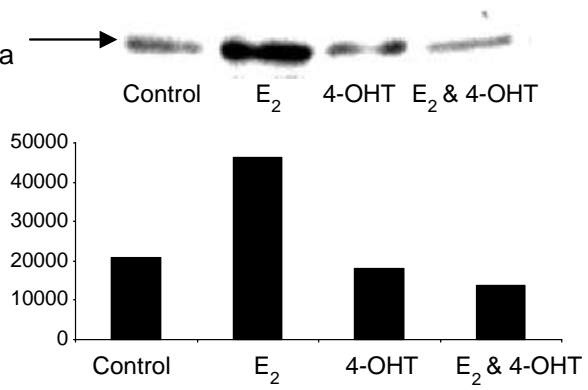

Figure 3 The ability of ER- $\alpha$ and ER- $\beta$ to differentially recruit SRC-3 was determined by co-immunoprecipitation of SRC-3 with the ER isoforms. Cell lysates from four primary breast cell cultures derived from HER2 positive (i) (ii) and HER2 negative (iii) (iv) patient tumours (incubated in the presence and absence of $17 \beta$-estradiol and 4-hydroxytamoxifen) were immunoprecipitated with anti-SRC-3 and subsequently immunoblotted with either anti-ER- $\alpha$ (i) (iii) or ER- $\beta$ (ii) (iv). Densitometric analysis of the protein bands provides graphical representation of the relative levels of protein interaction with SRC-3. Results are representative of those obtained from three separate experiments.

tumour tissue. A positive association between SRC-3 and ER- $\alpha$ expression and conversely an inverse relationship between expression of ER- $\beta$ and SRC-3 were observed. However, associations between ER- $\alpha$ and SRC-3 have been previously examined, while some studies have described a positive relationship between ER- $\alpha$ and SRC-3 (Iwase et al. 2003), others have not (Hudelist et al. 2003). SRC-3 was found to enhance oestrogen-dependent induction of cyclin D1 expression by ER- $\alpha$, furthermore, transcription was completely abolished by the addition of pure or partial anti-oestrogens (Planas-Silva et al. 2001).

SRC-3 Expression

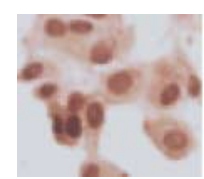

SRC-3

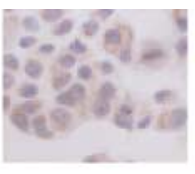

IgG Control

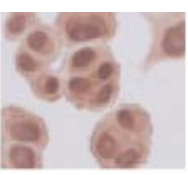

GAPDH siRNA

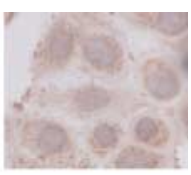

SRC-3

siRNA
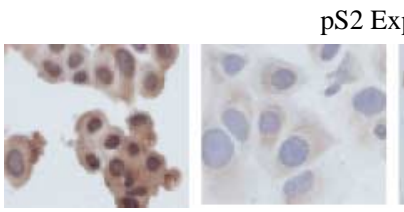

pS2

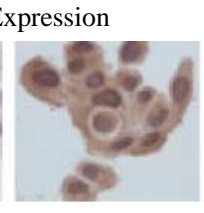

GAPDH SiRNA

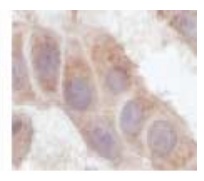

SRC-3

SiRNA

Figure 4 Immunocytochemical staining of SRC-3 and the oestrogen receptor target gene, pS2, with matched IgG controls in endocrine-sensitive MCF7 breast cancer cells post transfection with either GAPDH siRNA or siRNA-SRC-3 (400X). Results are representative of those obtained in three separate experiments. 

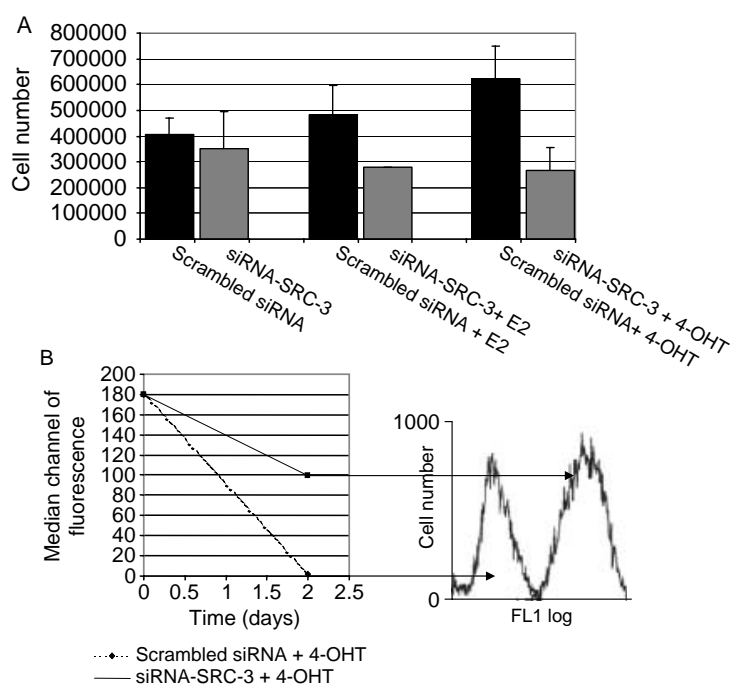

Figure 5 (A) The influence of $17 \beta$-estradiol and $4-\mathrm{OHT}$ on endocrine-resistant LY2 cell proliferation $24 \mathrm{~h}$ post-transfection with either siRNA-SRC-3 or scrambled SiRNA, as determined by counting the number of viable adherent cells. Results are representative of those obtained in three separate experiments. (B) Decline in fluorescent intensity overtime due to cell proliferation. LY2 cells were labelled with CFSE and transfected with siRNA-SRC-3 or scrambled siRNA and subsequently treated with 4-OHT. Arrows indicate a representative flowcytometry generated fluorescent histogram from LY2 cells treated with tamoxifen.

Our investigation showed recruitment of SRC-3 to the ER-ERE complex in untreated primary breast tumour cells and following treatment with $17 \beta$ estradiol. A role for HER2 in ER-growth factor crosstalk has previously been proposed (Johnston et al. 2003, Schiff et al. 2003), most notably, HER2 has been implicated in the enhancement of SRC-3 co-activator activity via protein phosphorylation (Font De Mora \& Brown 2000). Recently, in tamoxifen-resistant cell lines engineered to overexpress HER2, tamoxifen-induced recruitment of SRC-3 to the promoter region of the ER target gene pS2 was demonstrated (Shou et al. 2004). In our study, we utilised primary breast cancer tumours cultured ex vivo to investigate the recruitment of SRC-3 to the ER-ERE thereby enabling us to make observations in the presence/absence of endogenous HER2 levels. We found increased levels of SRC-3 at the response element in HER2 positive tumours, in contrast there was no increase in recruitment observed in HER2 negative samples. Moreover, increased SRC-3 protein expression was detected in cells treated with tamoxifen, but not $17 \beta$ estradiol, compared with control. These data further implicate tamoxifen-induced SRC-3-ER- $\alpha$-mediated gene transcription in the presence of an active HER2 MAP kinase pathway.

Specific co-activator-nuclear receptor interactions are thought to allow selective regulation of target genes through distinct histone acetylation (Li et al. 2003). Both ER- $\alpha$ and ER- $\beta$ have a strong affinity preference for particular co-activators, which may be mediated through isoform specific utilization of different LXXLL motifs for their interaction with p160 proteins (Wong et al. 2001). Molecular studies have shown that SRC-3 selectively enhances ER- $\alpha$ and progesterone receptor, but not ER- $\beta$-dependent gene transcription (Suen et al. 1998). However, others have observed SRC-3 ligand-dependent interactions with both ER- $\alpha$ and ER- $\beta$ (Bai \& Giguere 2003). In vitro studies have demonstrated that while oestrogen enhances the affinity of ER- $\alpha$ and ER- $\beta$ for p160 co-activators, tamoxifen and other ER modulators inhibit this interaction (Wong et al. 2001). Of interest however, in transfected kidney cell lines, co-expression of the proto-oncogene HER2 has been shown to specifically enhance ER- $\alpha$, but not ER- $\beta$, SRC-3 associations (Bai $\&$ Giguere 2003).

In this study, SRC-3 immunoprecipitates of HER2 negative breast tumours showed oestrogen-induced protein interactions between SRC-3 and both ER- $\alpha$ and ER- $\beta$, which were diminished by the ER modulator tamoxifen. However, in HER2 positive breast cancer tumours although there was oestrogen-induced protein interactions between SRC-3 and ER- $\beta$ there was no increase in interactions with ER- $\alpha$. Surprisingly, increased SRC-3-ER- $\alpha$ interactions in the HER2 positive tumours were only observed in the presence of tamoxifen. These tamoxifen-induced associations were ER isoform specific and were not observed for ER- $\beta$. These data suggest that in breast cancer, growth factor signalling may in part drive tamoxifen-induced ER- $\alpha-$ SRC-3 interactions.

We also found that knockdown of the $S R C-3$ gene at the mRNA level retards cell proliferation in HER2 positive, tamoxifen resistant, breast cancer cells in vitro. Indeed, SRC-3 appears to be so intrinsic to cell growth that the inhibitory effect was observed even when cells were treated with oestrogen and tamoxifen. The fundamental influence of the co-activator on cell growth suggests that its role is not simply mediated through nuclear receptors but may be channelled through various transactivators. However, the magnitude of increased recruitment of SRC-3 to ER- $\alpha$, in HER2 positive tumour cells when treated with tamoxifen provides evidence of one mechanism at play in endocrine therapy resistance. 
The significance of ER- $\alpha-\mathrm{SRC}-3$ interactions in breast cell cultures derived from HER2 positive patient tumours, in relation to endocrine resistance is supported by the strong association detected between the expression of ER- $\alpha$ and SRC-3 in our cohort of breast tumour patients. Taken together, these data provide evidence of a tamoxifen-induced selective interaction between ER- $\alpha$ and SRC-3, which may in part explain differential associations between expression of ER isoforms and resistance to endocrine treatment in breast cancer.

\section{Acknowledgements}

The authors declare that there is no conflict of interest that would prejudice the impartiality of this scientific work.

\section{References}

Anzick SL, Kononen J, Walker RL, Azorsa DO, Tanner MM, Guan XY, Sauter G, Kallioniemi OP, Trent JM, Meltzer PM et al. 1997 AIB1, a steroid receptor coactivator amplified in breast and ovarian cancer. Science $\mathbf{2 7 7}$ 965-968.

Bai Y \& Giguere V 2003 Isoform-selective interaction between estrogen receptors and steroid receptor coactivators promoted by estradiol and ErbB-2 signaling in living cells. Molecular Endocrinology 17 589-599.

Fleming FJ, Hill ADK, McDermott EW, O'Higgins NJ \& Young LS 2004a Differential recruitment of co-regulatory protein steroid receptor co-activator-1 and silencing mediator for retinoid and thyroid receptors to the estrogen receptor - estrogen response element by $\beta$-estradiol and 4-hydroxytamoxifen in human breast cancer. Journal of Clinical Endocrinology and Metabolism 89 375-383.

Fleming FJ, Myers E, Kelly G, Crotty TB, McDermott EW, O'Higgins NJ, Hill ADK \& Young LS 2004b Expression of SRC-1, AIB1 and PEA3 in HER2 mediated endocrine resistant breast cancer; a predictive role for SRC-1. Journal of Clinical Pathology 57 1069-1074.

Font De Mora J \& Brown M 2000 AIB1 is a conduit for kinase-mediated Growth Factor signaling to the estrogen receptor. Molecular and Cellular Biology 20 5041-5047.

Harvey JM, Clarke GM, Osborne CK \& Allred DC 1999 Estrogen receptor status by immunohistochemistry is superior to the ligand binding assay for predicting response to adjuvant endocrine therapy in breast cancer. Journal of Clinical Oncology 17 1474-1482.

Hudelist G, Czerwenka K, Kubista E, Marton E, Pischinger K \& Singer CF 2003 Expression of sex steroid receptors and their co-factors in normal and malignant breast tissue: AIB1 is a carcinoma-specific co-activator. Breast Cancer Research and Treatment 78 193-204.
Iwase H, Omoto Y, Toyama T, Yamashita H, Hara Y, Sugiura H \& Zhang Z 2003 Clinical significance of AIB1 expression in human breast cancer. Breast Cancer Research and Treatment 80 339-345.

Johnston SR, Head J, Pancholi S, Detre S, Martin L-A, Smith IE \& Dowsett M 2003 Integration of signal transduction inhibitors with endocrine therapy: an approach to overcoming hormone resistance in breast cancer. Clinical Cancer Research $9524 \mathrm{~S}-532 \mathrm{~S}$.

Li X, Wong J, Tsai SY, Tsai MJ \& O’Malley BW 2003 Progesterone and glucocorticoid receptors recruit distinct coactivator complexes and promote distinct patterns of local chromatin modification. Molecular and Cellular Biology 23 3763-3773.

List HJ, Reiter R, Singh B, Wellstein A \& Riegel AT 2001 Expression of the nuclear co-activator AIB1 in normal and malignant breast tissue. Breast Cancer Research and Treatment 68 21-28.

Mann S, Laucirica R, Carlson N, Younes PS, Ali N, Younes A, Li Y \& Younes M 2001 Estrogen receptor beta expression in invasive breast cancer. Human Pathology 32 113-118.

Myers E, Fleming FJ, Crotty TB, Kelly G, McDermott EW, O'Higgins NJ, Hill ADK \& Young L S 2004 The inverse relationship between ER- $\alpha$ and SRC-1 predicts patient outcome in endocrine resistant breast cancer. British Journal of Cancer 91 1687-1693.

Osborne CK, Bardou V, Hopp TA, Chamness GC, Hilsenbeck SG, Fuqua SAW, Wong J, Allred DC, Clark GM, Schiff R et al. 2003 Role of the estrogen receptor co-activator AIB1 (SRC-3) and HER2nu in tamoxifen resistance in breast cancer. Journal of the National Cancer Institute 95 353-361.

Paech K, Webb P, Kuiper GG, Nilsson S, Gustafsson J, Kushner PJ \& Scanlan TS 1997 Differential ligand activation of estrogen receptors ER- $\alpha$ and ER- $\beta$ at AP-1 sites. Science 227 1510-1580.

Paruthiyil S, Parmar H, Keretatte V, Cunha GR, Firestone G \& Leitman DC 2004 Estrogen receptor $\beta$ inhibits human breast cancer cell proliferation and tumour formation by causing a G2 cell cycle arrest. Cancer Research 64 423-428.

Planas-Silva MD, Shang Y, Donaher JL, Brown M \& Weinberg R A 2001 AIB1 enhances estrogen-dependent induction of cyclin D1 expression. Cancer Research $\mathbf{6 1}$ 3858-3862.

Schiff R \& Osborne CK 2005 Endocrinology and hormone therapy in breast cancer. New insight into estrogen receptor-alpha function and its implication for endocrine therapy resistance in breast cancer. Breast Cancer Research 7 205-211.

Schiff R, Massarweh S, Shou J \& Osborne CK 2003 Breast cancer endocrine resistance: how growth factor signaling and estrogen receptor co-regulators modulate response. Clinical Cancer Research 9 447s-454s.

Shao W, Kranickas Keetin E, McDonnell DP \& Brown M 2004 Coactivator AIB1 links estrogen receptor transcriptional activity and stability. PNAS 101 11599-11604. 
Shou J, Massarweh S, Osborne CK, Wakeling AE, Ali S, Weiss H \& Schiff R 2004 Mechanisms of tamoxifen resistance: increased estrogen receptor-HER2/neu cross talk in ER/HER2-positive breast cancer. Journal of the National Cancer Institute 96 895-897.

Smith CL, Nawaz Z \& O’Malley BW 1997 Coactivator and corepressor regulation of the agonist/antagonist activity of the mixed antiestrogen, 4-hydroxytamoxifen. Molecular Endocrinology 11 657-666.

Speirs V, Malone C, Walton DS, Kerin MJ \& Atkin SL 1999 Increased expression of estrogen receptor $\beta$ mRNA in tamoxifen-resistant breast cancer patients. Cancer Research 59 5421-5424.

Suen CS, Berrodin TJ, Mastroeni R, Cheskis BJ, Lyttle CR \& Frail DE 1998 A transcriptional coactivator, steroid receptor coactivator-3, selectively augments steroid receptor transcriptional activity. Journal of Biological Chemistry 273 27645-27653.

Torres-Arzayus MI, Font de Mora J, Yuan J, Vazquez F, Bronson R, Rue M, Sellers WR \& Brown M 2004 High tumour incidence and activation of the PI3K/AKT pathway in transgenic mice define AIB1 as an oncogene. Cancer Cell 6 263-274.

Wong CW, Komm B \& Cheskis BJ 2001 Structure-function evaluation of ER- $\alpha$ and $\beta$, interplay with SRC family coactivators. ER selective ligands. Biochemistry 40 6756-6765.

$\mathrm{Xu}$ J, Liao L, Ning G, Yoshida-Komiya H, Deng C \& O'Malley BW 2000 The steroid receptor coactivator SRC-3 (p/CIP/RAC3/AIB1/ACTR/TRAM-1) is required for normal growth, puberty, female reproductive function, and mammary gland development. PNAS 97 6379-6384. 